\title{
An Empirical study on machine assembly efficiency improvement based on lean six sigma technique
}

\author{
Chien-Chih Wang*, Yu-Hsun Li, Chun-Ting Liu \\ ${ }^{a}$ Department of Industrial Engineering and Management Ming Chi University of Technology, New Taipei, Taiwan \\ *Corresponding Author: ieccwang@mail.mcut.edu.tw
}

\begin{abstract}
In this paper, the Lean Six Sigma (LSS) was proposed to improve production fluence of production recycle time and manufacturing cost in the production system. The overall response and production efficiency were bottlenecks while changing or discovering the problems of business process in the practical. First, using the cause-and-effect matrix and failure mode and effects analysis decide the factors that affect working hours and recycle time. Next, the Value Stream Mapping is used to highlight the bottlenecks of the overall work after determining the strategies and modified goals. Finally, the Lean Production Approach is employed to solve problems. With the examples of co-operative manufacturer is analyzed and discussed. The results show that inventory carries rate can be reduced from $41.6 \%$ to $20.8 \%$ and create NT $\$ 15.57$ million net profits. Lean Six Sigma is proved to be efficient and clear that it does not just change the influenced factors but also improve the overall work and shipment proficiency.
\end{abstract}

Keywords: lens assembly machine, lean production, DMAIC, inventory carry rate.

\section{Introduction}

In the operating model of the enterprise, if the turnover of inventory and production line are inflexible, it will lead to the capital being idle, thus affecting the competitiveness of the company. Especially for the small and medium-sized enterprises, they can only carry out the improvement and updating of the production process under the limited environment due to resource constraints and the talent shortage. In this paper, under the framework of Lean Six Sigma (LSS), adopted the case manufacturer of the optical lens assembly as an example to develop the model, which can efficiently improve the turnover speed of the working flow and reduce the overall working hours.

Lean Six Sigma integrates the management of Lean production and Six Sigma technology [1,2]. To use lean management method to solve the problem of time or inventory related to quality to achieve the goals of the smooth process and the elimination of stagnation and sluggish of inventory [3]. Six Sigma focuses on how to make the production and the enterprise process more efficient [4]. Lean Six Sigma focuses on the quality and speed of the process. When Six Sigma is unable to improve the process speed significantly, Lean Six Sigma can be adopted to reach the goal. On the whole, Lean Six Sigma can improve customer's satisfaction, reduce the cost, improve quality, accelerate the process speed and improve the capital investment to maximize shareholder's value [5].

There are five significant steps in the six sigma method, including Define, Measure, Analyze, Improve, and Control [6]. The definition is the first thing to be done when implementing a six-sigma project, which is to define the key issues facing the whole improvement. At this stage, it can be roughly divided into project procedures, goals, and requirements of the boss or customer, and project process.

In the project process, the overall business process and the problems occurred are described first, and compared to the original set of goals, the project needs the resources and time to complete. In this stage, C\&E, FMEA and SIPOC methods are mostly used to find out the possible causes of the process. The questions or demands raised by the boss or customer areas measurable or quantifiable as possible, which enables subsequent comparisons to be made in stages such as measurement and analysis. The measurement phase is to data-visual the problem process discovered during the definition phase and use the value stream map to highlight the data. The purpose of the value stream map (VSM) is to describe all the steps of the process, including all the processes required from input to output, and indicate how 
much Value is added to the product or service between the processes; or how much waste is implied in the process. The analysis phase is to find the root cause of the problem and analyze the influence degree of the possible influencing factors found in the measurement stage. The purpose is to list and explain the problems caused by all factors, and then integrate and correlate the relevant factors in the description, and then further explore these factors. The improvement phase is to use the key factors found in the analysis stage to put forward the improvement plan and data, carry into the simulation for analysis, and compare the differences before and after the improvement. The control phase records and standardizes the process of analysis improvement so that the problem or process does not revert to the wrong direction. This part needs to be completed through the formal SOP file building, training, procedure chart.

The case company produces high precision automation equipment in Taiwan; its main products are automation equipment and high optical lens assembly equipment (Figure 1).

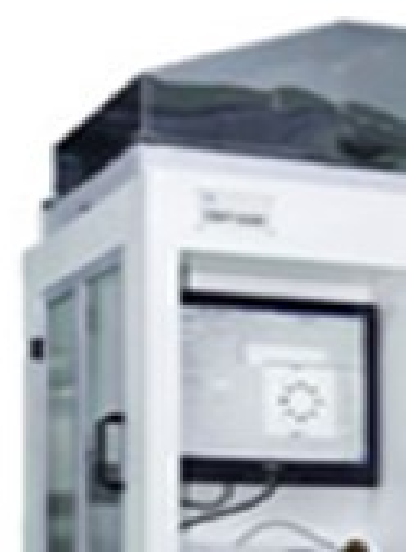

Fig. 1 The production equipment of co-operative manufacturer.

The industry has the characteristics of short delivery time, high cost, and short cycle. The main reason lies in that the enterprises will update, increase or replace the production equipment in order to meet the demand for the order production under the conditions of the peak season and recovery of the electronics industry, and the increase of the consumption intention. However, the conditions of the orders refunded, reduced or delayed are easily caused by the change of the market and the imitation of competitors. Therefore, efficiently shortening delivery time is a significant topic for the equipment manufacturers. Based on the decision of the case company, this study reduced the original working hours of $132 \mathrm{hrs}$ by $5 \%$ to $126 \mathrm{hrs}$ as the standard working hours.

\section{Research Method}

In this study, the lean production and six sigma method were used to improve the company's assembly machine. Lean Production and Six Sigma DMAIC technique are adopted in this study to improve the company's assembly machine. Five thoughts of Lean Production, including Specify the Value, Identify the Value Stream, Flow, Pull and Perfection, are integrated to DMAIC structure, confirming the appreciated value from Define phase, searching the factors to affect the value process in Measure Phase, knowing the impact magnitude in Analyze Phase, executing the improvement method in Improve Phase, for example, Lean Production Pull and modular operation are imported and the statistical validation is adopted for the result verification, and finally concluding the operation and converging the variation in Control Phase so as to pursue perfection. Through this integration, LSS can be smoothly imported in current practical work and it is certain that errors will not be made once again so as to achieve the benefit of Lean and Value.

\section{Case study and analysis}

In recent years, the poor equipment assembly efficiency cannot meet the customer's demand, so the order-receiving rate of the case company is in decline, causing the gradual decline of the company's profitability. There are three main problems after the diagnosis, which are respectively the procurement process, schedule management, and working hour management.

\subsection{Define Phase}

First of all, the workstation, which may have abnormalities in the process as well as the reasons are sorted in, define phase with the respective use of SIPOC and Cause-and-Effect matrix.

Then, the sorting relationship between the customer's expectation and the process station is listed with a Cause-and-Effect matrix, with the results shown in Table 1. The primary customer's expectations are large fund flow, long production cycle, high-idled inventory and low utilization of productivity, whose weight is respectively 7,9 , 5,5 . The results showed that the schedule of production 
schedule station is not accurate, and the time used for the assembly of modules is too long, which are the focuses needed improving.

\subsection{Measure Phase}

The value stream mapping will be used in Measure Phase to analyze the operation process, find out the steps with non-value added and put forward the goal for the expected improvement. Figure 2 is the value stream drawing of the current assembly process, and it is found from the results that the waiting time of average $1.09 \mathrm{hrs}, 1.126 \mathrm{hrs}$ and $1.17 \mathrm{hrs}$ are produced respectively between the machine arranging/ XY line rail screw assembly station, tie line station of disk fixation, fixation station of mesa module and HEAD set station. Besides, the whole machine module delay of average $1.974 \mathrm{hrs}$ and $1.36 \mathrm{hrs}$ are produced respectively between the HEAD set station and AIR UNIT assembly station, static IPC station and the setting station for the parameters of the whole machine.

\subsection{Analyze Phase}

The statistical analysis of the current conditions will be conducted concerning the bottleneck found in the value stream drawing in Analysis Phase.

Regarding the working hour of the whole machine, 95\% confidence interval is 131.616 and 133.753 , which exceeds $6.6 \mathrm{hrs}$ on average compared with $126 \mathrm{hrs}$ standard working hour. As for the working time of XY the line rail screw assembly station, the $95 \%$ confidence interval is 15.277 and 15.928, with an average of more than 1.77 hours, while the standard working time was 17.37 hours. Regarding disk fixed tie line working hour, 95\% confidence interval is 23.40 and 23.75 , which exceeds $3.57 \mathrm{hrs}$ on average compared with the $20 \mathrm{hrs}$ standard working hour. Regarding the fixed working hour of the working platform module, 95\% confidence interval is 9.08 and 9.71 , which exceeds $1.14 \mathrm{hrs}$ on average compared with $8.25 \mathrm{hrs}$ standard working hour. Regarding the working hour of the HEAD set station, 95\% confidence interval is 22.01 and 22.99 , which exceeds $3.92 \mathrm{hrs}$ on average compared with $18.58 \mathrm{hrs}$ standard working hour. Regarding the working hour of static IPC station, 95\% confidence interval is 8.42 and 9.05 , which exceeds $0.07 \mathrm{hrs}$ on average compared with the $8.67 \mathrm{hrs}$ standard working hour.

\subsection{Improve Phase}

As the case company belongs to project and polytrope assembly process, which is suitable for JIT mode assembly, as the auto assembly line. After the confirmation of the order and at the same time of the main structure operation, it is required that the assembly of each module line should begin to act, and they should be added in the body assembly one by one at the time of the integral assembly of back-end production line.

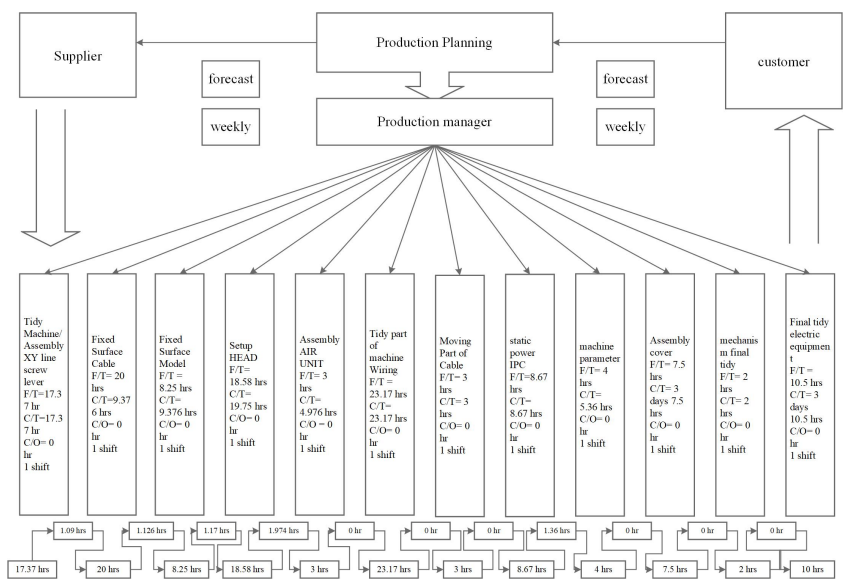

Fig. 2 The value stream mapping of operation process

After the analysis of overall improvement results, it is found that the average working hours before and after the improvement of the working hours of the whole machine are respectively $132.68 \mathrm{hrs}$ and $110.741 \mathrm{hrs}$, and $\mathrm{p}$-value $=0.000$ after the statistical test. This result is better than the set target of $126 \mathrm{hrs}$.

\subsection{Control Phase}

Control phase is mainly to evaluate whether the improved strategy can genuinely make the profit. Figure 3 is the comparative results before and after the improvement of 20 process steps. The average working hours change from $34.495 \mathrm{hrs}$ before the improvement to $15.250 \mathrm{hrs}$ after the improvement ( $\mathrm{p}$-value $<0.0001$ ).

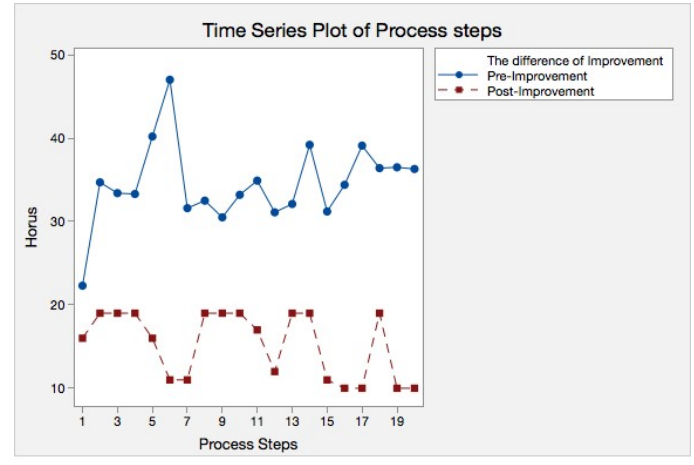

Fig. 3 The different between pre-improvement and post-improvement 


\section{Conclusions}

From the study results, can be found in the improvement procedure of Lean Six Sigma that LSS can break through the abnormal thinking that the change of working hour in the site manufacturing operation is the production efficiency, which is assumed previously by the superintendent.

In the evaluation of finished projects, the research achievements can reduce the production cycle from original $132 \mathrm{hrs}$ to $111 \mathrm{hrs}$. The inventory turnover rate changes from original $20.8 \%$ (per quarter) to $41.6 \%$ (per quarter). The improvement results above can annually create NT $\$ 15.57$ million financial effect as estimated by the financial department.

\section{References}

(1) Baker, B. "Innovating Lean Six Sigma: A Strategic Guide to Deploying the World's Most Effective Business Improvement Process", Quality Progress, Vo. 50, No.2, p.60, 2017.

(2) Pepper, M. P., \& Spedding, T. A. (2010). The evolution of lean Six Sigma. International Journal of Quality \& Reliability Management, Vo. 27, No.2, pp.138-155, 2010.

(3) Krafcik, J. F. "Triumph of the lean production system", MIT Sloan Management Review, Vol. 30, No.1, p.41, 1988.

(4) Pyzdek, T., \& Keller, P. A. The six sigma handbook (Vol. 4). New York, NY: McGraw-Hill Education, 2014.

(5) Arnheiter, E. D., \& Maleyeff, J." The integration of lean management and Six Sigma", The TQM magazine, Vol. 17, No.1, pp. 5-18, 2005.

(6) Ansar, A. R., Shaju, S. U. C., Sarkar, S. K., Hashem, M. Z., Hasan, S. K., \& Islam, U. "Application of Six Sigma using Define Measure Analyze Improve Control (DMAIC) methodology in Garment Sector", Independent Journal of Management \& Production, Vol. 9, No.3, pp.810-826, 2018. 